\title{
Dissemination Strategies for Cultural Heritage: The Case of the Tomb of Zechariah in Jerusalem, Israel
}

\author{
Monica Bercigli (D) \\ DIDA Department of Architecture, University of Florence, 50122 Florence, Italy; monica.bercigli@unifi.it
}

Received: 27 December 2018; Accepted: 17 January 2019; Published: 23 January 2019

\begin{abstract}
This paper reports the research carried out using Structure from Motion survey techniques, which were developed on the basis of previous surveys and their subsequent representation through two-dimensional (2D) and three-dimensional (3D) drawings of the tomb, comparing them with drawings and watercolors by several painters of the past. This survey technique enables the reconstruction of three-dimensional models through photographs. The aim of this work is to define a procedural process which allows accurate and reliable three-dimensional reconstructions to be performed for the acquisition of knowledge and the dissemination of cultural heritage, taking advantage of representation and visualization techniques that have been developed in the last decade and that are based on historical references. The variety of digital products which can be produced (video games, 3D models, prints, websites, and augmented reality applications) allows a different approach to the representation to be taken, thereby re-evaluating limits, aims, and expressive potential. The virtual representative systems, enriched with cultural content, scientific information, and data, enhance the participation and awareness of knowledge of the final users of the products and are able to increase the interaction between the user and the information.
\end{abstract}

Keywords: digital survey; virtual reality; serious game; rupestrian architecture

\section{Introduction}

The rapid evolution of technology in recent decades has greatly shifted the attention of the scientific community towards possible scenarios which have so far been "ignored". Digital databases represent a very rich source of knowledge, and therefore rules must be established, or guidelines dictated, for their correct acquisition, storage, and dissemination. Principles must be shared for the validation of information and collected data, while databases must be built to protect this heritage so that it can be consulted and used by anyone who needs it. Methodological reference systems, papers, and documents have been developed over the years. In this regard, we refer to the activities of ICOMOS$^{1}$ (the International Council on Monuments and Sites) and CIPA (the International Committee for Documentation of Cultural Heritage). CIPA was founded in 1968 jointly with ISPRS (the International Society for Photogrammetry and Remote Sensing) to facilitate the transfer of technology from the measurement sciences into the heritage documentation and recording disciplines. Furthermore, the London Charter, ${ }^{2}$ in the updated version of 2009, proposed to define the objectives and principles related to the use of "computer-based visualization methods in relation to intellectual integrity, reliability, documentation, sustainability, and access" [2].

1 ICOMOS is an international, non-governmental organization of heritage professionals engaged in the conservation of places of cultural value and dedicated to the conservation of the world's historic monuments and sites, founded in 1965 following the adoption of the Charter for the Conservation and Restoration of Monuments and Sites in Venice in 1964. Here we refer to the ICOMOS Charter for the Interpretation and Presentation of Cultural Heritage Sites [1].

2 The London Charter for the Computer-Based Visualization of Cultural Heritage was conceived in 2006 as a means of ensuring the methodological rigour of computer-based visualization for researching and communicating cultural heritage. 
New digital technologies are revolutionizing the way people communicate and, simultaneously, it is changing the way we perceive the environment around us. Many tools are available for the use and enjoyment of heritage, both tangible, such as monuments and historical sites, and intangible, such as the traditions, sounds, and artistic practices of a community. The most commonly used tools are smartphones and tablets, namely those that allow individuals to interact with real-time virtual environments or artifacts, both through virtual reality (VR) and augmented reality (AR) applications; even museums are starting to use more advanced technologies such as viewers, earphones, and gloves, as they allow more immersion. ${ }^{3}$

Today, thanks to the development of more manageable digital platforms that are able to accommodate even more complex content, such as high-definition three-dimensional (3D) models, 'virtual museums' can be considered as an extension of real museums, as they are not the simple replication of the real ones; they instead integrate functions that allow the visit to be personalized.

Ultimately, the exponential development of the entertainment and gaming industry is also affecting the field of cultural heritage (Figure 1), where it is taking hold of the concept of serious games, the most common definition of which is given by Michael et al. [3] as "games that do not have entertainment, enjoyment, or fun as their primary purpose" (Anderson et al. [4]; Georgopoulos et al. [5]; Ioannides et al. [6]).

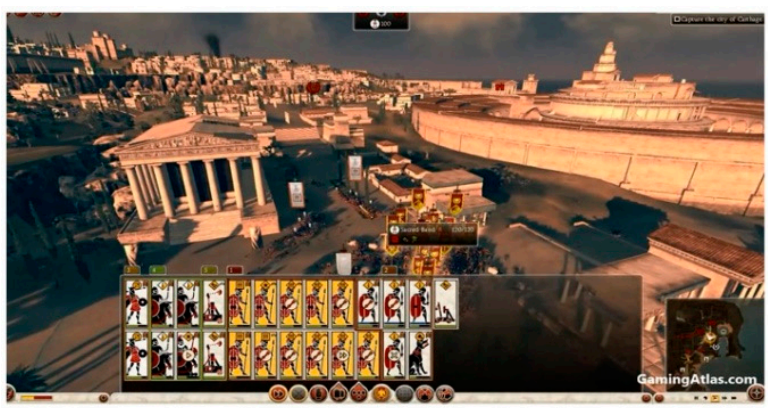

Rome: Total War II - The Siege of Carthage

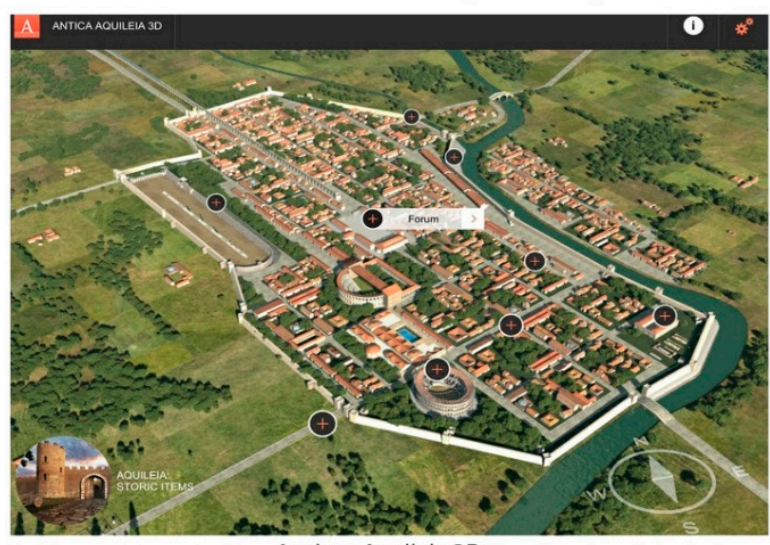

Ancient Aquileia 3D

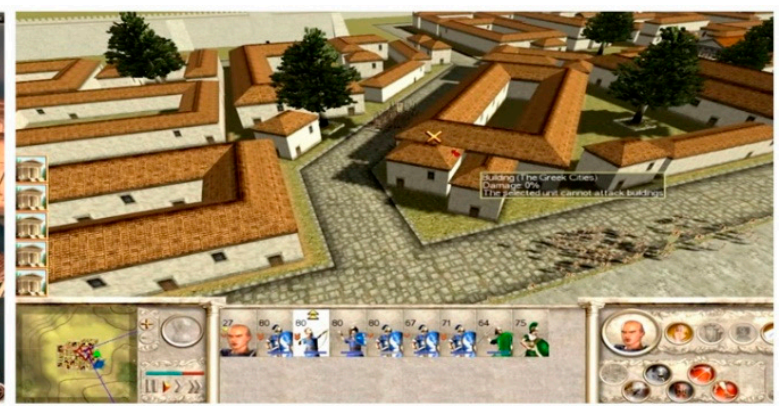

Rome: Total War - The Siege of Syracuse

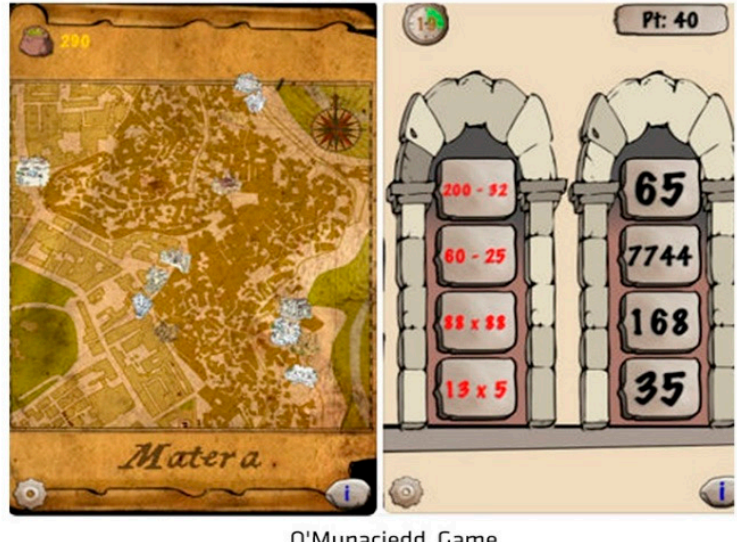

O'Munaciedd Game

Figure 1. Examples of serious games as tools for visualization and virtual fruition of cultural heritage: Rome. Total War II-The Siege of Carthage, Rome. Total War-The Siege of Syracuse, Ancient Aquileia 3D (https:/ / www.worldsummitawards.org/winner/ancient-aquileia-3d-app), O'Munacied Game (http://munaciedd.pa.itd.cnr.it/).

3 For example, the Cleveland Museum of Art in the USA features digital interactive installations and a gallery that allows visitors to explore the works of painters on a large multi-touch micro-tile screen. The Museum of the Ara Pacis in Rome (Italy), on the other hand, hosts a specific museum tour for blind people. Visitors suffering from blindness or visual pathologies can partake in a multi-sensory and inclusive experience. The MUSE Museum in Trento hosts a project called GO! Muse, an augmented reality application that allows visitors to view dinosaurs as they hypothetically originally appeared. 
The skepticism of museum structures and institutions in the use of these innovations, which are now widely used in other sectors, is unfortunately still present. Although the main cause is often to be found in the scarce economic availability, it is necessary for the cultural community to make the most of the potential of these tools through the promotion and financing of both consolidated and experimental equipment.

It is possible to affirm that games are an important medium, but they are still undervalued in terms of their potential for the sharing of heritage. The relationship between 3D models and video games is a valuable field of investigation for the development of tools useful for the dissemination of cultural heritage and to increase the awareness of it to a large audience.

\section{Fast Survey and 3D Modeling}

The great development of the city of Jerusalem during the 70s allowed us to learn more about some parts and aspects of the city, particularly those concerning its ancient necropolis. During those years, many tombs of the First Temple period were discovered. The extension of the city's suburbs also resulted in the excavation of many tombs of the Second Temple period and a large number of ossuaries were found. These discoveries have provided a lot of new information about the funerary architecture, funerary customs, and modes of crucifixion. The object of study in this paper is the so-called tomb of Zechariah, in the Kidron Valley at the foot of the Mount of Olives, on the southeastern side of the old city walls. It is a real rupestrian monument and is part of a group of four tombs, some of which are carved directly into the rock. The tomb of Zechariah is composed of a cubic block of rock that measures about $6 \mathrm{~m}$ on the side, obtained by removing the surrounding rock so as to form an area in the center which stands isolated. Each of the walls is decorated by a pair of columns and two semi-columns, the latter of which are adjacent to the pillars with a square section at the corners. All are equipped with Ionic capitals. All around the cornice there is a decoration of acanthus leaves a little less than a meter high, dominated by an obtuse pyramid of about three meters in height that forms the summit of the tomb; on the whole, the monument measures about $9 \mathrm{~m}$ in elevation (Brockedon et al. [7]).

This paper reports the experience of the documentation and 3D modeling of the tomb carried out using "expeditious" surveying techniques.

The choice of a fast methodology, based on SfM (Structure from Motion) photogrammetric techniques and subsequent post-production by semi-automated processes, enables the quick development of 3D models. In addition, by using high-resolution cameras, it is possible to obtain realistic models that are just like real artifacts and that can then be used in virtual and augmented reality applications.

The procedure included the photographic acquisition of the entire rock complex and, in particular, of the exterior of the tomb of Zechariah. The pictures were taken with a reflex camera and were processed using Agisoft Photoscan software (Figure 2), where a complete 3D model with textures was created, starting with the photos' alignment and the building of a point cloud. Based on historical documentation and 2D drawings of previous surveys, the model was resized to its correct size (Figure 3).

The next step was to export the model in the .obj format in order to import it into Geomagic Wrap and process the 3D model by making improvements to the polygonal mesh. Here, automatic sections were also obtained, which, by generating splines and polylines exportable in .igs format, were used as the basis for the construction of a NURBS ${ }^{4}$ model. This was conducted in order to reconstruct the original appearance of Zechariah's tomb, cleared of signs of decay and neglect. Referring to the drawings of the existing surveys, the two main bodies of the building were modeled, as well as all the details of the capitals, columns, and half-columns (Figure 4). The base and the steps leading to the tomb

4 NURBS (Non Uniform Rational Basis-Spline) are very flexible curves and allow to draw complex shapes. Modeling through NURBS surfaces generated by extrusion, revolution, lofting patching (etc.) of NURBS curves, allows to accurately represent both common analytic shapes and free-form shapes. 
were also modeled in order to reconstruct the tomb in its entirety. Over the course of many centuries, tombs were built along most of the steep terrain of the Kidron Valley and many of these tombs are located in the immediate vicinity of the monumental tombs. Over time, their initial appearance has been significantly altered.
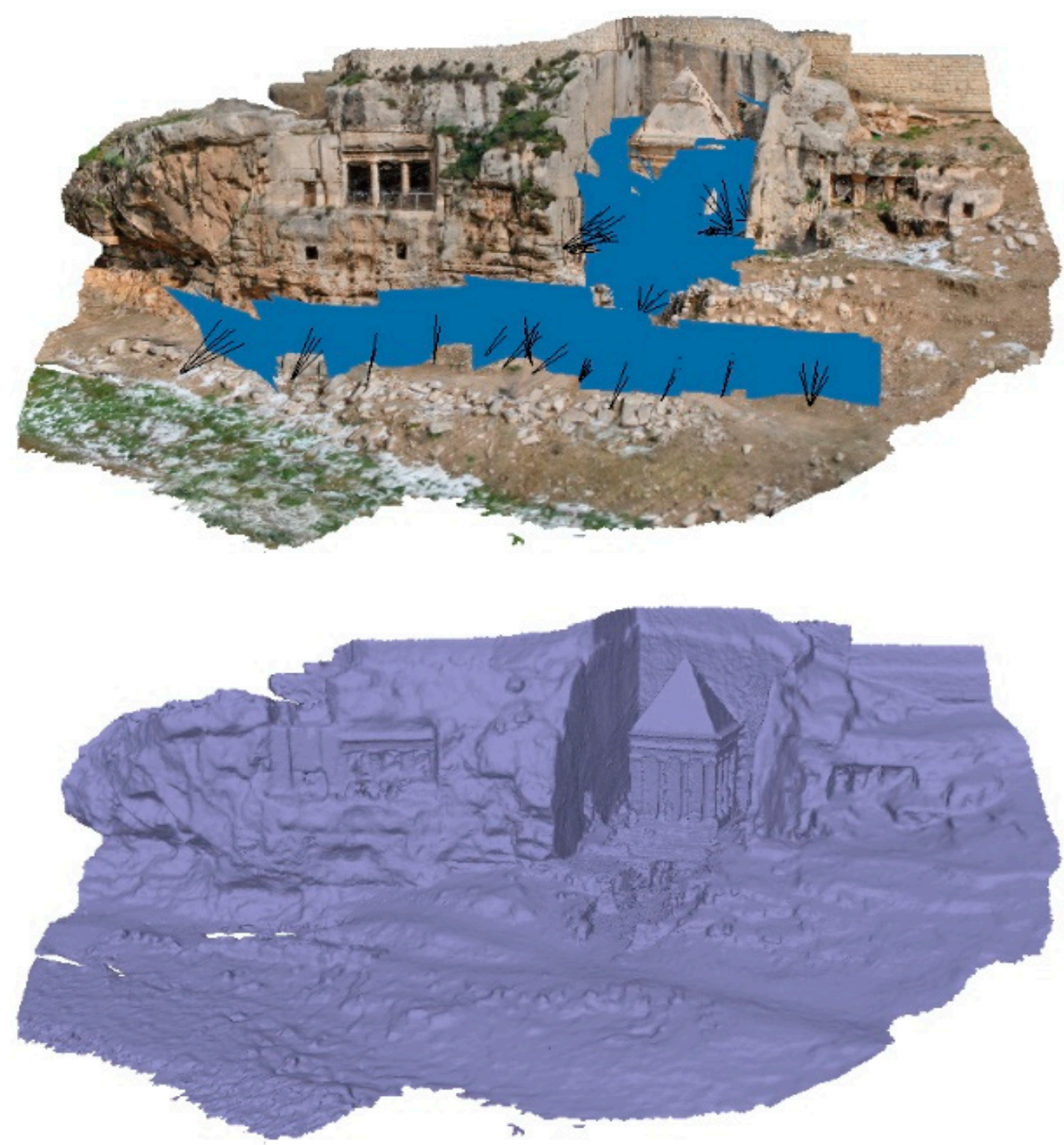

Figure 2. The SfM (Structure from Motion) process within Agisoft Photoscan. 

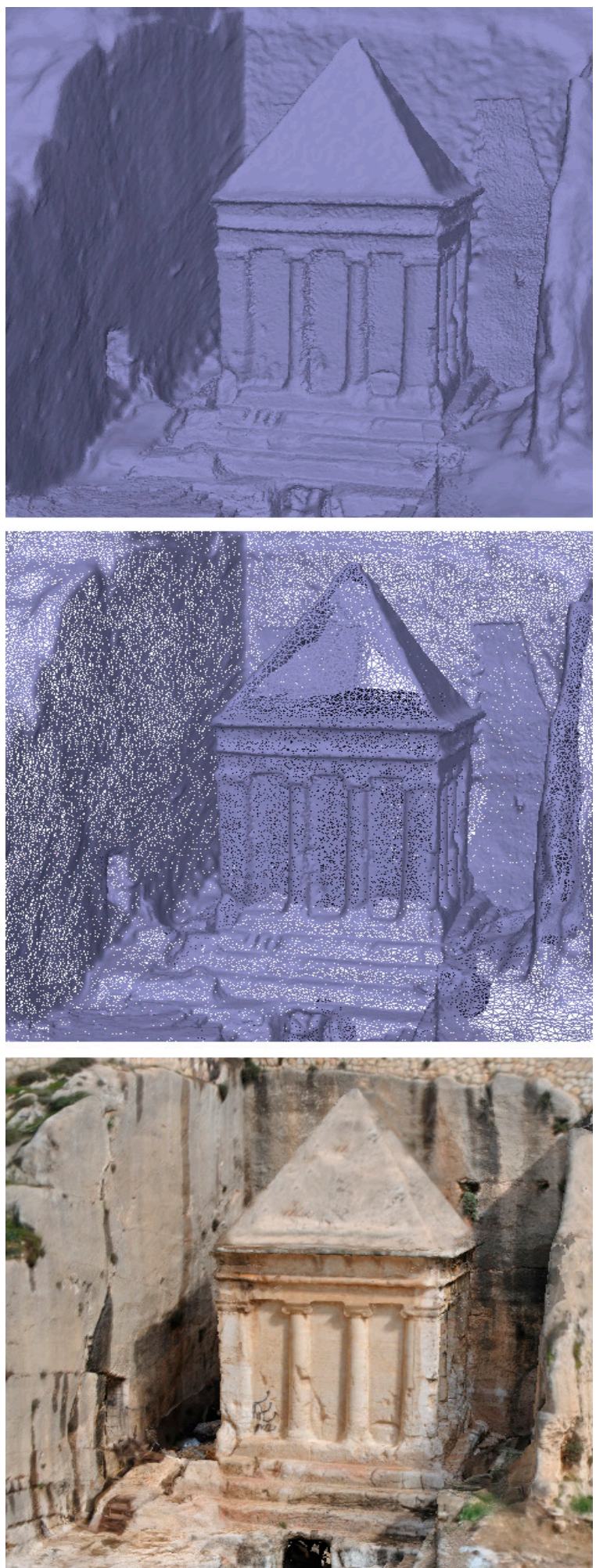

Figure 3. The SfM (Structure from Motion) process within Agisoft Photoscan, showing details of Zechariah's tomb. 

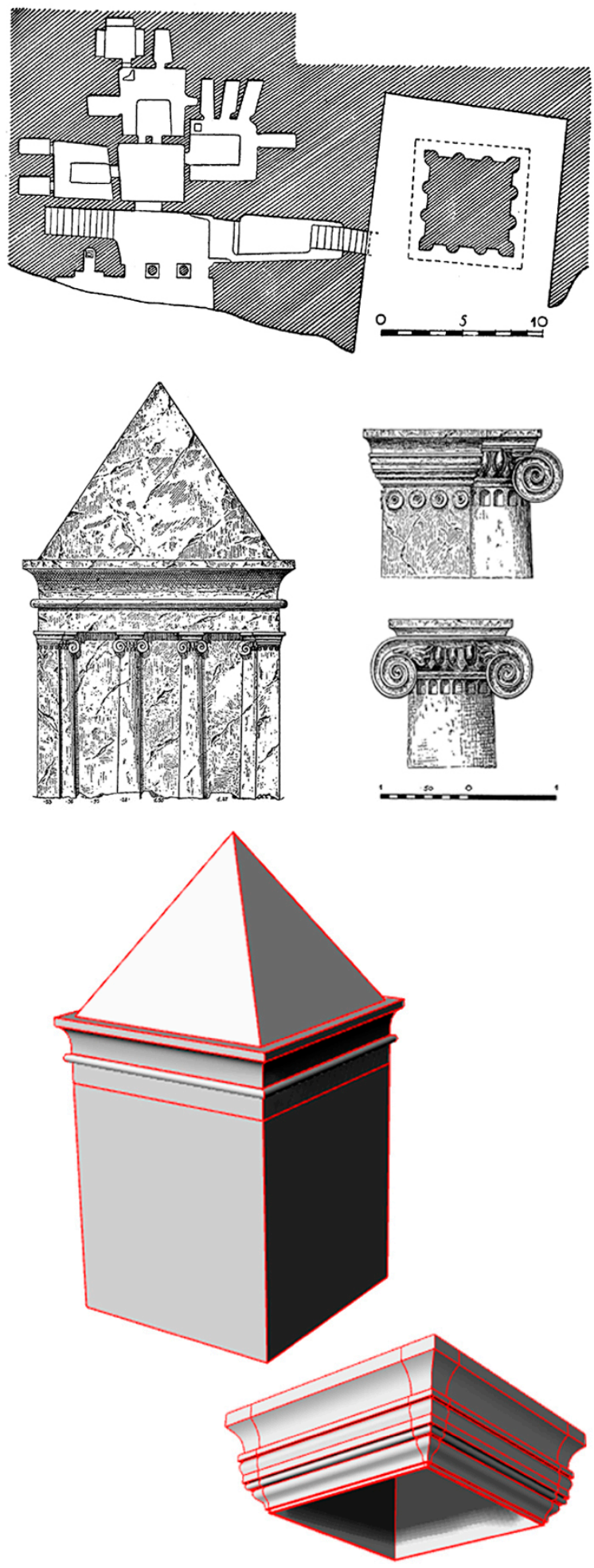

Figure 4. The NURBS modeling process, starting from 2D (two-dimensional) drawings of previous surveys (http:/ / www.christusrex.org/www1/ofm/sbf/Books/dispense/TopogrGer117_TombeErod. pdf) [8].

The purpose of the task was to create a 3D model in a rapid manner that looks as similar as possible to the site's original appearance, both from a metric and a material point of view. This methodological procedure also leads to the rapid execution of models that can be inserted into interactive digital contexts (Bercigli [9]). 
Digital visualization is of great importance for the success of the representation of the object, although it cannot take into account the peculiar characteristics that each place has (Norberg-Schulz [10]). For this reason, drawings and historical representations of this place, produced by skilled sketchers of the past, have been studied. The suggestions of these artists determine the base used to recreate the atmosphere and the setting where the 3D model is to be inserted.

The current appearance of the tomb complex is not very different from what was represented in the past, except for the level of the land that was excavated in recent times (Figure 5).

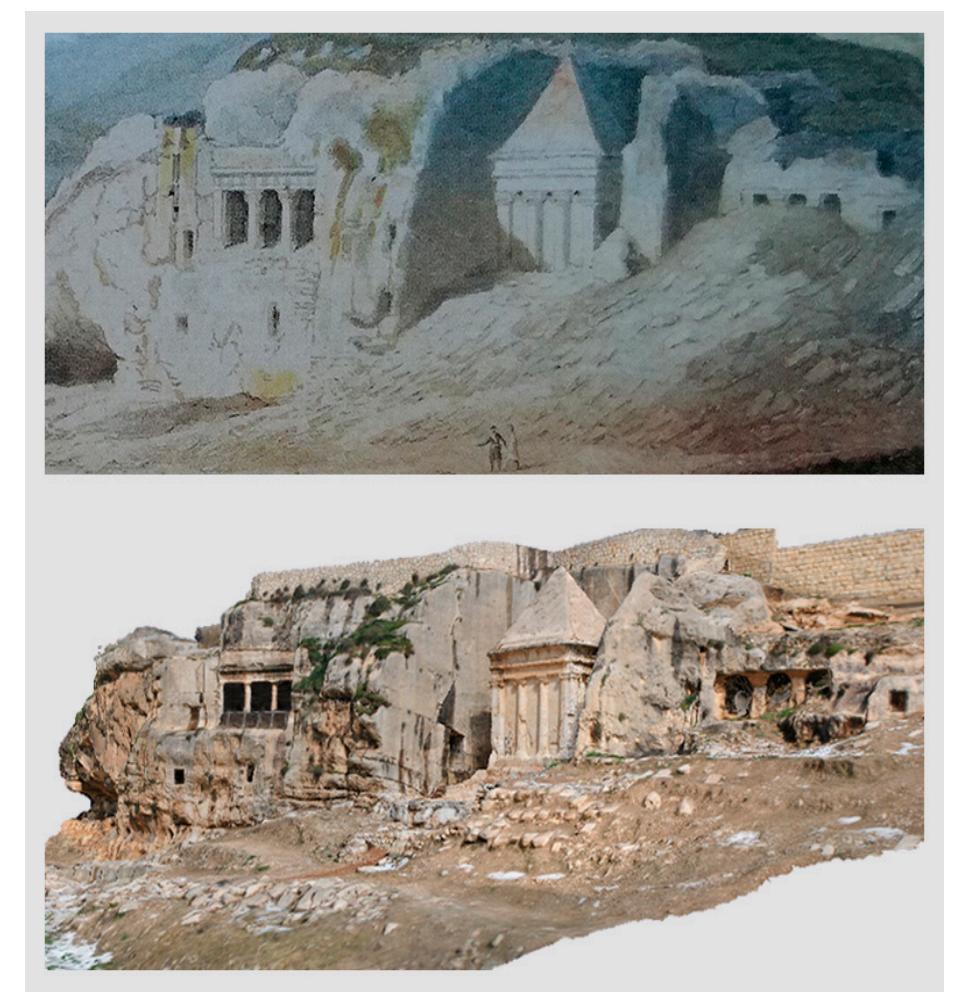

Figure 5. A comparison of the textured 3D model with a lithograph from Brockedon et al. [7] (p.155).

The level of the ground today is noticeably lower as it was excavated in recent times.

\section{Innovative Fruition Systems}

The visualization tools employed in this study are still under development and the construction of the scenario in Unity 3D is at the very first stage. All of the aspects regarding the storytelling, the game design, and the graphical features are still in the stages of preparation.

Thus far, the mesh model derived from photogrammetry has been imported into the scene as the general environment, and the 3D NURBS model has been completed with a simple texture with diffuse and bump channels, imported together with all of the assets useful for virtual interaction with the site. In the development of a serious game, the choice of the game structure and contents cannot be neglected. Among the most important factors to ensure the success of and interaction with the game, there are an effective plot and narrative, as well as the dynamism and fluidity of the game itself. The 3D models used must be low-poly and easily manageable for real-time visualization, both on web platforms and via portable devices. The combination of all of these components constitutes a very powerful means for the valorization of heritage and its dissemination.

With the establishment of serious games as a means of communication and the dissemination of heritage, a new type of 'virtual museum' is set up. Prensky [11] asserted that "learning via digital games is one way to reach digital natives in their native languages".

Those that are today defined as 'virtual museums' initially were configured as digital copies of real museums, where all of the assets held by the museum and the information relating to them 
was collected and archived. Before the invention of the Internet, virtual museums corresponded to CD-ROMs on which the databases were dumped in the form of catalogs, where it was possible to search for works using keywords.

The possibilities offered by the 'web network' in terms of the diffusion and sharing of 'virtual museums' have been enormous, but they have also had to deal with the different structuring of content with respect to that found in real museums. With the publication on the network of museums, there have been technical problems and interoperability issues between digital databases and information searches.

This type of museum guarantees a participatory interaction during the "visit" and keeps the user's involvement alive, encouraging them to improve their knowledge and awareness of cultural heritage. The so-called virtual museums are not simply replications of real ones, as they instead integrate functions that allow individuals to personalize their visit (Mortara et al. [12]). Through some tools, it is possible, for example, to manipulate objects and to move and rotate them without the risk of damaging them. The visitor can walk freely within the virtual space, or stop the visit and resume it at any time, choosing which actions to take without having to follow a predefined path.

\section{Conclusions}

The perception of the space and of the artifacts affects all human senses and must therefore be encouraged in order to ensure the active participation of the visitor in the 'narration'. Through the use of 'virtual reality' it is possible to build any kind of scenario, infinitely changeable and upgradeable, in order to make available to the public a wide database that is not accessible through any other tour arrangement.

However, it is necessary to know the advantages and disadvantages of a virtual reality system: Achieving convincing 3D models and high-level simulations involves using the best software and hardware. It is therefore important to make clear which goals one wants to achieve and how fast one can reach them. Finally, an important aspect not to be underestimated in the development of 'virtual worlds' and, more specifically, of serious games is the creation of an application that does not lose sight of the primary objective of producing information and disseminating culture; otherwise, there is a risk of exalting the aesthetic aspects of the systems to the detriment of the informative/narrative feedback of the virtual ecosystem (Forte, [13]).

Funding: This research received no external funding.

Conflicts of Interest: The authors declare no conflict of interest.

\section{References}

1. ICOMOS Charter. The ICOMOS Charter for the Interpretation and Presentation of Cultural Heritage Sites. Available online: https: / / www.icomos.org/en/charters-and-other-doctrinal-texts (accessed on 4 January 2019).

2. London Charter. The London Charter: For the Computer Based Visualisation of Cultural Heritage. Available online: http:/ / www.londoncharter.org/downloads.html (accessed on 14 January 2018).

3. Michael, D.; Chen, S. Serious Games: Games that Educate, Train and Inform; Thomson Course Technology PTR: Boston, MA, USA, 2006.

4. Anderson, E.F; McLoughlin, L.; Liarokapis, F.; Peters, C.; Petridis, P.; de Freitas, S. Developing Serious Game for the Heritage: A State of Art Review. Virtual Real. 2010, 14, 255. [CrossRef]

5. Ioannides, M.; Magnenat-Thalmann, N.; Papagiannakis, G. (Eds.) Mixed Reality and Gamification for Cultural Heritage; Springer: Cham, Switzerland, 2017.

6. Georgopoulos, A.; Kontogianni, G.; Koutsaftis, C.; Skamantzari, M. Serious Games at the Service of Cultural Heritage and Tourism. In Tourism, Culture and Heritage in a Smart Economy; Springer Proceedings in Business and Economics; Katsoni, V., Upadhya, A., Stratigea, A., Eds.; Springer: Cham, Switzerland, 2017.

7. Brockedon, W.; Croly, G. (Eds.) Terra Santa. Litografie Tratte Dai Disegni Eseguiti sul Posto da David Roberts, R.A. Corredati Dalle Descrizioni Storiche del Reverendo George Croly L.L.D.; White Star: Liverpool, UK, 2000. 
8. Available online: http://www.christusrex.org/www1/ofm/sbf/Books/dispense/TopogrGer117_ TombeErod.pdf (accessed on 15 March 2017).

9. Bercigli, M. The transparency of 3D models: The case of the Byzantine church at Masada in Israel. In 3D ModelingE BIM, Progettazione, Design, Proposte per la Ricostruzione; Empler, T., Ed.; DEI Tipografia del Genio Civile: Roma, Italy, 2017; pp. 164-177.

10. Norberg-Schulz, C. Genius Loci; Electa: Milano, Italy, 1979.

11. Prensky, M. Digital Natives, Digital Immigrants. Part 1. In On the Horizon; MCB University Press: Bingley, UK, 2001; Volume 9, pp. 1-6.

12. Mortara, M.; Catalano, C.E.; Bellotti, F.; Fiucci, G.; Houry-Panchetti, M.; Petridis, P. Learning cultural heritage by serious games. J. Cult. Herit. 2014, 15, 318-325. [CrossRef]

13. Forte, M. Dal Reale al Virtuale Verso una Comunicazione Arricchita? In Archeologia e Calcolatori 15; All'insegna del Giglio: Firenze, Italy, 2004; pp. 423-448.

2019 by the author. Licensee MDPI, Basel, Switzerland. This article is an open access article distributed under the terms and conditions of the Creative Commons Attribution (CC BY) license (http:// creativecommons.org/licenses/by/4.0/). 